\title{
How Web browsers shape users' understanding of networks
}

\author{
Louise Sheeran and M. Angela Sasse \\ Department of Computer Science, University College London \\ L.Sheeran@cs.ucl.ac.uk
}

\section{Jon Rimmer and Ian Wakeman}

COGS, University of Sussex

Falmer

\section{Contents}

1. Introduction

2. Web study

3. Results

4. How do error messages influence users' models?

5. Consequences for Web browser design

6. Further work

7. Acknowledgements

8. References

\section{Introduction}

The Web is one of the most popular Internet applications today. However, transmissions on the Internet are not very robust, and users are inevitably faced with breakdown situations. To take appropriate recovery actions, a basic user's model of how the Internet works, that is, an application specific model of the important network components relevant to the application in question, is deemed to be useful.

Norman (1986) advocates the use of conceptual design, a method proposed to ensure that users develop appropriate users' models of systems through interacting with the system image (screen design, documentation, etc.) (Figure 1). To achieve this, the system image is based on a clear and concise design model, which is the model that users should ideally acquire. The research project, which the study reported here is part of, is using conceptual design to provide guidelines for the design of network applications which will facilitate users constructing appropriate users' models of the underlying network.

Figure 1 Conceptual design. Based on Norman (1986) 


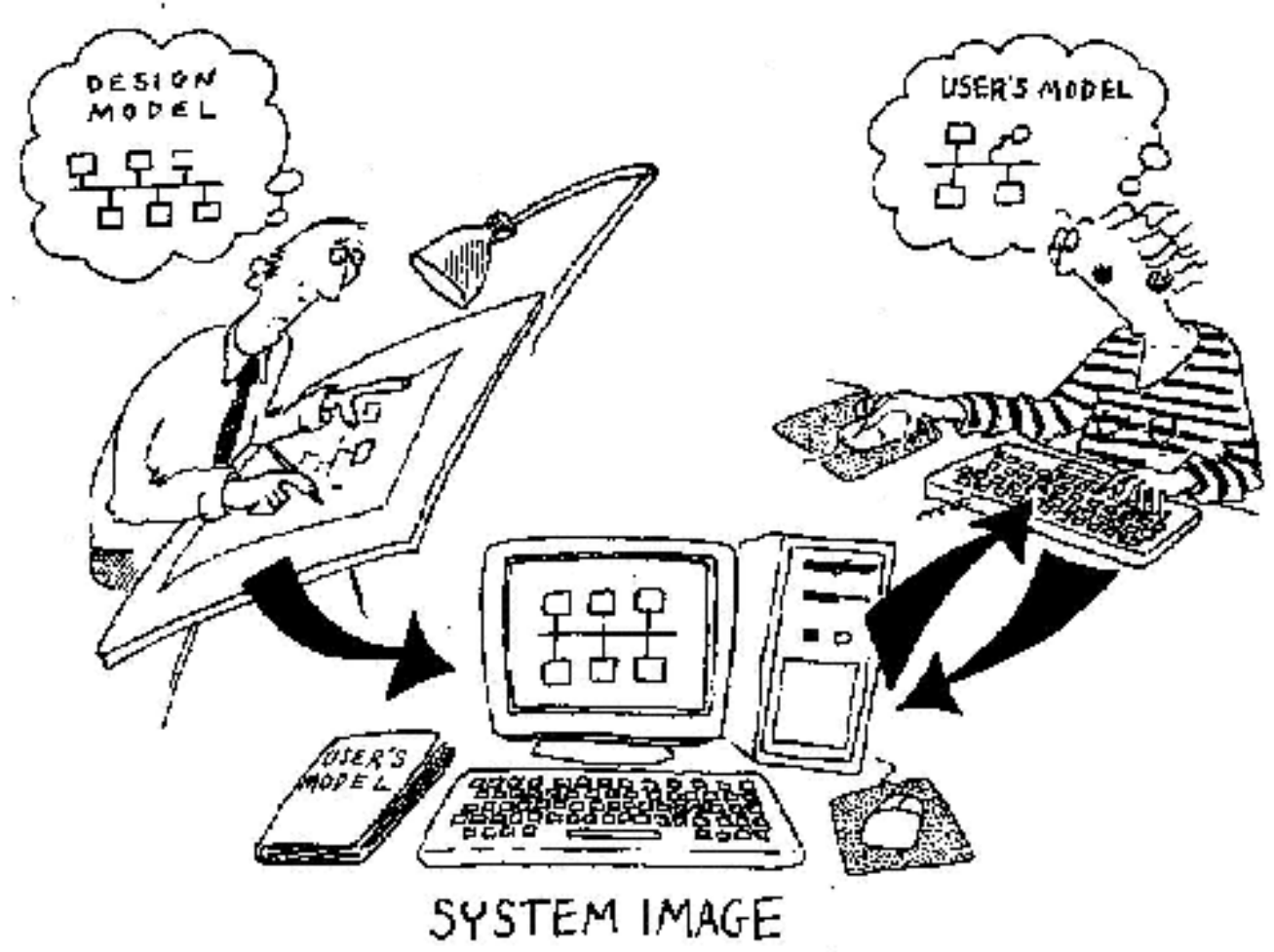

In the case of Web browsers, where the location of the breakdown situation determines if the user can repair it or not, an appropriate model of Web browsing and appropriate wording of error messages are particularly important.

This article is a report on a study that investigated users' models of Web browsing and users' reaction to error messages produced by Netscape Communicator 4.6 and Microsoft Internet Explorer 4. In particular, the study was designed to show how users deal with the network terminology used in error messages and if the language used in error messages affects their users' models.

\section{Web study}

A series of Web pages were created around ten scenarios, designed to take the user through the task of finding a recipe and signing an on-line guestbook. The route was riddled with obstacles and situations, which the participants had to deal with while thinking aloud. The scenarios in the study included the following three breakdown situations which all caused error messages to be displayed in the browser:

- A link containing a spelling mistake in the filename

- A link to a page on a server, but invalid port number specified

- A link to a page on a non-existent server.

There were 35 participants (18 male, 17 female). Of these 24 classified themselves as intermediate users, 7 as experts and 4 as novices. Each participant used either Netscape Communicator or Microsoft Internet Explorer, depending on their normal choice of Web browser. The study took approximately 30 minutes per participant. 


\section{Results}

In general the participants did not pay much attention to the error messages, and all feedback on error messages (apart from one participant) was negative, fir example:

'I infer the meaning of Error 404 is just like Core Dumped or Memory Error 08693, it just means that you can't get what you want' (P28, Internet Explorer).

The gist of the comments was that error messages are difficult to understand and not very useful. The error messages simply signal that "something" is wrong, and to find out what is wrong, users relied on experience. The following IE error message was displayed in both scenarios 2 and 3 (the site name was different in each case):

'Internet Explorer cannot open the Internet site http://www-mice.cs.ucl.ac.uk:100/ . A connection with the server could not be established.'

Not surprisingly, there was hardly any difference in the reasons given for the error message in each case by the novice and intermediate users. Most of their answers fell into two categories:

- A problem with the connection (modem problem or 'local' ISP server down)

- A problem with the remote server (down or busy).

The few novice and intermediate participants who did suggest that the site might not exist were the ones who had tried to guess a company's Web address and discovered that failed attempts resulted in that particular error message.

The inadequacy of error messages has resulted in a standard recovery action procedure being adopted by many. If following a link results in an error message, participants will 'try again' immediately and if it still 'does not work', they either give up or, if it is a link they are particularly interested in, they will try again later, irrespective of what the error message says.

\section{How do error messages influence users' models?}

Error messages help give users the terminology of the Web browsing domain, but fail to provide the model on which to glue the many new terms and concepts. Nine of the novice and intermediate participants did not know which part of the Web address constituted the server's name, and as to a definition of a server, the explanations included: the main connection..., the bit ..., the hub ..., the people ..., the thing ..., the page ..., the computer ..., the information ....

Note that only one out of the eight words is 'computer'. The terminology, however, is an important step towards acquiring a user's model, as language is instrumental in mental model construction (Clark and Sasse, 1997, Johnson-Laird 1983, Aitchison 1994, Stevenson 1993). What is needed now is a structure on which to pin the words.

\section{Consequences for Web browser design}

When pushed to explain each of the error messages and their cause, nearly all novice and 
intermediate participants failed to give a satisfactory explanation. They were unable to make adequate distinctions between a problem being related to the server (down or non-existent) or the page/file structure itself. This is partly due to poor wording of error messages, but followup questions also revealed inappropriate users' models of the Web browsing process.

An easy fix, which does not require a change of the traditional and very ingrained navigational metaphor used by both Netscape Communicator and Microsoft Internet Explorer, would be to communicate a coherent model of Web browsing in the error messages and help systems. The model would graphically show the elements involved in requesting a Web page and how they relate to the Web address. Figure 2 shows an example of what the top level of such a model might look like. The error messages would point to where in the process the breakdown situation had occurred, give the possible reasons and suggest recovery actions.

Figure 2 Suggested design model for Web browsing

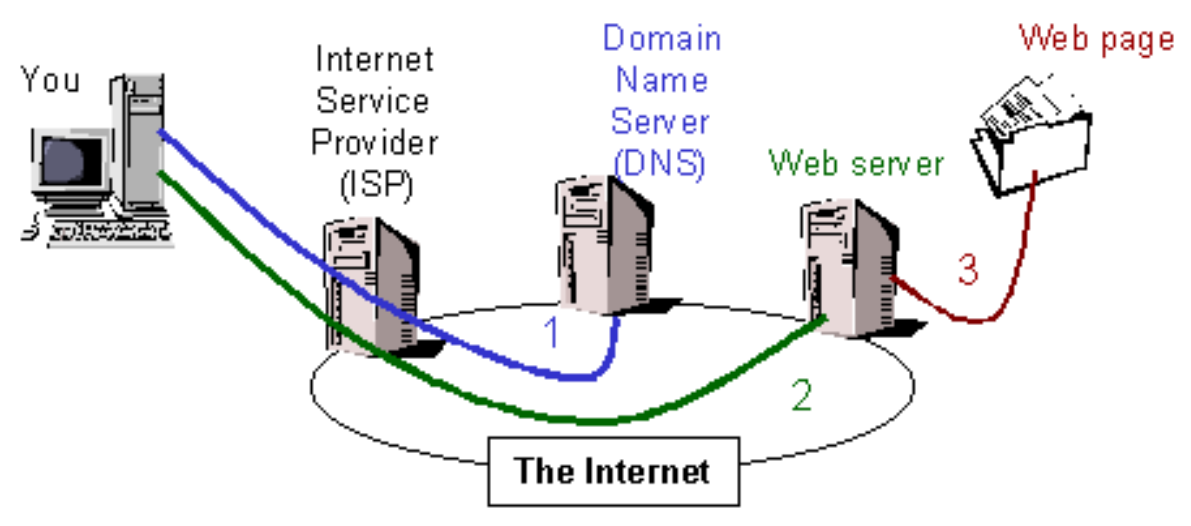

The study has been followed up by a number of in-depth interviews with intermediate Web users. Results from this study show, independently from breakdown situations, that intermediate users have very patchy and inappropriate users' models of Web browsing (Sheeran et al. 2000).

\section{Further work}

The model shown in Figure 2 has been incorporated into redesigned error messages in a Web browser. A study is currently being designed in which the redesigned error messages will be compared to the error messages produced by Microsoft Internet Explorer 5, in order to see to what extent each set of error messages influences users' models of Web browsing. Results from this study will be included in the full paper.

\section{Acknowledgements}

The study was carried out under the EMMANATE project, which is funded by the EPSRC.

\section{References}

Aitchison, J. 1994. Words in the mind. 2nd ed. Oxford: Blackwell. 
Clark, L. and Sasse, M.A. 1997. Conceptual design reconsidered - the case of the Internet session directory tool. In: Proceedings from HCI'97. Bristol: Springer.

Johnson-Laird, P.N. 1983. Mental models. Cognitive science. Cambridge, Massachusetts: Harvard University Press.

Norman, D.A. 1986. Cognitive engineering.. In: User centred system design, by D.A. Norman and S.W. Draper (eds.) Hillsdale, New Jersey: Lawrence Erlbaum.

Sheeran, L., M.A. Sasse, J. Rimmer and Wakeman, I. 2000. Research note RN/00/25, Dept of Computer Science, UCL.

Stevenson, R.J. 1993. Language, thought and representation. Chichester, England: John Wiley.

\section{Disclaimer}

Articles published in SAJIM are the opinions of the authors and do not necessarily reflect the opinion of the Editor, Board, Publisher, Webmaster or the Rand Afrikaans University. The user hereby waives any claim he/she/they may have or acquire against the publisher, its suppliers, licensees and sub licensees and indemnifies all said persons from any claims, lawsuits, proceedings, costs, special, incidental, consequential or indirect damages, including damages for loss of profits, loss of business or downtime arising out of or relating to the user's use of the Website. 
ISSN 1560-683X

Published by InterWord Communications for the Centre for Research in Web-based Applications, Rand Afrikaans University 